\title{
The Impact of Cognitive Reserve on the Neuropsychological Functioning of Hispanic Patients with Minor Neurocognitive Disorder
}

\author{
Jorge A. Herrera Pino ${ }^{1,2}$, Nora Dieguez ${ }^{1,3}$, Jose Armas ${ }^{1,2}$ \\ ${ }^{1}$ Medical Care Consortium, Inc., Miami, USA \\ ${ }^{2}$ Herbert Wertheim College of Medicine, Florida International University, Miami, USA \\ ${ }^{3}$ Neurobehavioral Institute of Miami, Coral Gables, Miami, USA \\ Email: jherrera@neurobehavioralmiami.com
}

Received August $7^{\text {th }}, 2013$; revised September $9^{\text {th }}, 2013$; accepted September $28^{\text {th }}, 2013$

\begin{abstract}
Copyright (C) 2013 Jorge A. Herrera Pino et al. This is an open access article distributed under the Creative Commons Attribution License, which permits unrestricted use, distribution, and reproduction in any medium, provided the original work is properly cited.
\end{abstract}

\begin{abstract}
The purpose of this study was to explore the impact of cognitive reserve, on the neuropsychological status of a sample of otherwise healthy Hispanic patients, who complained of memory difficulties, and thus were suspected to present minor neurocognitive disorder. To this effect, 100 consecutive cases referred for neuropsychological evaluation by their primary care physicians comprised the initial sample. Two groups of 32 patients were formed on the basis of their scores in the Cognitive Reserve Questionnaire (CRQ) that was administered to all participants. The results obtained by both groups in an eclectic battery of neuropsychological instruments were compared. The results indicated that the CRQ High Score group had significantly better performance than the CRQ Low Score group in the tests administered, except those tapped into memory processes. This was interpreted, to be related to the fact that all of these patients fell into the category of mild cognitive impairment of the amnestic type, as neither group performed well in these specific instruments. The findings of this study were interpreted to lend support to the notion that better cognitive reserve was associated with better cognitive status in the later years of life.
\end{abstract}

Keywords: Cognitive Reserve; Neuropsychological Evaluation; Mild Neurocognitive Disorder; Mild Cognitive Impairment

\section{Introduction}

The seminal work of Yaakov Stern (2002) opened the doors to a whole field of scientific endeavor related to the concept of cognitive reserve. In this regard, this concept has been the focus of a significant amount of research in recent years (cf. Stern, 2006, 2009; Stern et al., 2003). At the center of the notion of cognitive reserve is the assumption that there are things people can do, to better their cognitive health, and to improve the chances of maintaining an adequate cognitive status throughout the aging process, or even when assailed by disease that would otherwise lead to impaired cognition (Vasile, 2013).

Patients who present to their primary care physicians or to specialists complaining of memory difficulties, have often been placed within the category of mild cognitive impairment, as per the original ideas proposed by Petersen (2004), Petersen et al. (2001), and Petersen et al. (1999). They were even diagnosed with mild cognitive impairment (MCI) of the amnestic type. There was also great concern regarding the rate of conversion of these patients to a full blown dementing disorder of primary degenerative type, such as Alzheimer's disease.

However, the term mild cognitive impairment, as such, while being a useful concept, was never made a diagnosis, even though some authors referred to it (cf. Albert et al., 2013). Recently, the fifth edition of the Diagnostic and statistical manual of mental disorders of the American Psychiatric Association (DSM-5; APA, 2013) includes the diagnosis of minor neuroncognitive impairment, within which mild cognitive impairment has been included. This is the term used throughout this paper to refer to the participants of this study.

\section{Methodology}

\section{Ethical Considerations}

This study was approved by the Institutional Review Board of the Medical Care Consortium, Inc., (MCCI) as an archival, cross-sectional, quasi-experimental research.

\section{Participants}

The participants of this study were 100 consecutive, otherwise healthy, Hispanic patients seen at the Cognitive Health Program of MCCI, who were referred by their primary care physicians for presenting memory complaints. MCCI is a multi-center organization that provides primary and specialized medical care in out-patient settings. The initial sample of 100 patients included 62 females and 38 males.

Two samples were derived on the bases of the scores obtained in the Cognitive Reserve Questionnaire (CRQ; Alberca Serrano, 1998) described below. The 32 patients with the high- 
est scores in the CRQ (CRQH) had an average score of 12.75 $(\mathrm{sd}=1.98)$, an average chronological age of 73.02 years $(\mathrm{sd}=$ $8.65)$, and an average of 13.78 years of education ( $\mathrm{sd}=4.03)$.

The 32 patients with the lowest scores in the CRQ (CRQL) obtained an average score of $4.00(\mathrm{sd}=2.07)$, they had an average chronological age of 70.19 years $(\mathrm{sd}=7.28)$, and an average level of education of 4.63 years $(\mathrm{sd}=3.49)$. As seen in Table 1, the means of both groups differed significantly in the scores obtained in the CRQ and in the level of education, but not in chronological age.

\section{Instruments and Procedures}

All participants were administered the CRQ, as well as an eclectic battery of neuropsychological instruments described below.

The Cognitive Reserve Questionnaire (CRQ; Alberca Serrano, 1998) was administered in its original version in Spanish. This instrument yields a total score of 25 and includes assessment of the following dimensions:

- Level of education

- Highest level of education of one of the parents

- Additional training or courses taken

- Occupation or profession

- Formal musical training or education

- Languages spoken at a conversational level

- Reading activity

- Intellectual games or pastime

In addition to the CRQ, all participants were administered an eclectic battery of neuropsychological instruments based on a process oriented, evidence based paradigm. The instruments included in this battery were the written (SDW); and oral (SDO) administrations of the Symbol Digit Modalities Test (Smith, 1973, 1982, 2002), the Controlled Oral Word Association Test (COW; Lezak, Howieson, \& Loring, 2004; Spreen \& Strauss, 1998), the Boston Naming Test (BNT; Kaplan, Goodglass, \& Weintraub, 1983, 1996), the administrations RAI (recall of the list in the first trial), RAV (recall of the list in the fifth trial), and RAD (recall of the list with a 20 minute delay) of the Rey Auditory Verbal Learning Test (Schmidt, 1996), the copy (ROC) and delayed (30 minute) (ROM) administrations of the Rey Osterrieth Complex Figure Test (Rey, 2003; Meyers \& Meyers, 1995), and the Revised Benton Visual Retention Test (BVR; Benton, 1974, 2002; Sivan, 1992). All neuropsychological tests were administered in Spanish, as this was the preferred language of all participants.

\section{Data Analysis}

Differences between the mean values obtained, by the two

Table 1.

Demographic data by group.

\begin{tabular}{cccc}
\hline & \multicolumn{3}{c}{ Groups by CRQ score } \\
\cline { 2 - 4 } & CRQLS N $=32$ & CRQHS N =32 & Student t \\
\hline CRQ & $4.00(2.07)$ & $12.75(1.98)$ & $-17.224^{*}$ \\
Age & $70.19(7.28)$ & $73.03(8.65)$ & -1.422 \\
Education (years) & $4.62(3.49)$ & $13.781(4.030)$ & $-9.705^{*}$ \\
\hline
\end{tabular}

CRQLS $=$ Cognitive Reserve Questionnaire Low Scoring, CRQHS $=$ Cognitive Reserve Questionnaire High Scoring, ( ) standard deviation, ${ }^{*} \mathrm{p} \leq 0.000$. groups of patients with high and low scores in the CRQ in the different measures included in this study, were analyzed by means of the Student-t statistical procedure.

\section{Results}

As noted above, Table 1 includes the differences between both groups of participants in the variables of scores in the CRQ, chronological age, and level of education. Table 2 shows the mean values obtained by both groups in the different instruments included in the neuropsychological battery administered to all participants.

An inspection of this table reveals that the mean score obtained by the CRQ High Scoring (CRQHS) group in the written administration of the Symbol Digit Modalities Test (SDW) was $26.59(\mathrm{sd}=9.70)$, while the corresponding value obtained by the CRQ Low Scoring (CRQLS) group was $12.78(\mathrm{sd}=9.05)$. The difference between these two means was found to be significant at the level of $p<0.000$, Relative to the oral administration of this instrument (SDO), the mean score obtained by the CRQHS group was $29.68(\mathrm{sd}=10.92)$, whereas the CRQLS group obtained a mean value of $15.25(\mathrm{sd}=10.31)$. Once again, the difference between the means of both groups was found to be significant at the level of $p<0.000$.

The results obtained by both groups in the Controlled Oral Word Association Test (COW) are as follows. The CRQHS group obtained a mean value of $24.65(\mathrm{sd}=8.61)$. The CRQLS group obtained a mean score of $15.68(\mathrm{sd}=7.68)$. The difference between these two means is statistically significant at the level of $p<0.000$.

A 30 item version of the Boston Naming Test (BNT; Saxton et al., 2000) was used as part of the neuropsychological test battery administered to all the participants of this study. The

Table 2.

Means and standard deviations in neuropsychological tests by group.

\begin{tabular}{cccc}
\hline & \multicolumn{3}{c}{ Groups by CRQ score } \\
\cline { 2 - 4 } NP Tests & CRQLS N $=32$ & CRQHS N $=32$ & Student t \\
\cline { 2 - 4 } SDO & $15.25(10.31)$ & $29.68(10.920$ & $-5.436^{*}$ \\
SDW & $12.78(9.05)$ & $26.59(9.70)$ & $-5.887^{*}$ \\
COW & $15.68(7.68)$ & $24.65(8.61)$ & $-4.393^{*}$ \\
BNT & $16.87(3.94)$ & $22.68(4.27)$ & $-5.654^{*}$ \\
RAI & $3.71(1.08)$ & $4.28(1.44)$ & -1.763 \\
RAV & $6.00(2.40)$ & $7.87(2.12)$ & $-3.304^{* *}$ \\
RAD & $4.40(2.48)$ & $5.87(2.70)$ & $-2.259^{* * *}$ \\
ROC & $22.01(7.40)$ & $30.23(4.44)$ & $-5.383^{*}$ \\
ROM & $6.29(3.35)$ & $10.71(5.40)$ & $-3.933^{*}$ \\
BVR & $2.12(1.56)$ & $3.75(1.79)$ & $-3.863^{*}$ \\
\hline
\end{tabular}

NP Tests $=$ Neuropsychological Tests, $\mathrm{CRQLS}=$ Cognitive Reserve Questionnaire Low Scoring, CRQHS $=$ Cognitive Reserve Questionnaire High Scoring, SDO = Symbol Digit Modalities Oral, SDW = Symbol Digit Modalities Written, COW = Controlled Oral Word Association, BNT = Boston Naming Test, RAI = Rey Auditory Verbal Learning (I), RAV= Rey Auditory Verbal Learning (V), RAD = Rey Auditory Verbal Learning (D), ROC = Rey Osterrieth Complex Figure Copy, $\mathrm{ROM}=$ Rey Osterrieth Complex Figure Memory, BVR $=$ Benton Visual Retention, ( ) standard deviation, ${ }^{*} \mathrm{p} \leq 0.000,{ }^{* *} \mathrm{p} \leq 0.002,{ }^{* * *} \mathrm{p} \leq 0.027$. 
mean score obtained by the CRQHS group in the BNT was $22.68(\mathrm{sd}=4.27)$, while the corresponding value obtained by the CRQLS group was 16.87 (sd = 3.94). The difference between these means was found to be statistically significant at the level of $p<0.000$.

The mean score obtained by the CRQHS group in the first administration of the list of words of the Rey Auditory Verbal Learning Test $(\mathrm{RAI})$ was $4.28(\mathrm{sd}=1.44)$, while the mean score for the CRQLS group was $3.71(\mathrm{sd}=1.08)$. The difference between these two means was not found to be statistically significant $(p=0.083)$. In the fifth administration of the list of words of this instrument (RAV), the mean score value for the CRQHS group was $7.86(\mathrm{sd}=2.12)$ and for the CRQLS group the mean score was $6.00(\mathrm{sd}=2.40)$. This difference in mean values was found to be significant at the level of $p=0.002$.

The mean score obtained by the CRQHS group in the delayed (20 minutes) administration of the list of words of the Rey Auditory Verbal Learning Test (RAD) was 5.87 ( $\mathrm{sd}=$ $2.70)$, with a corresponding mean value of $4.40(\mathrm{sd}=2.48)$ for the CRQLS group. The difference between these means was found to be statistically significant at the level of $p=0.027$.

Relative to the Rey Osterrieth Complex Figure Test, the findings were as follows. The CRQHS group obtained a mean score of $30.23(\mathrm{sd}=4.44)$ in the copy administration (ROC). The CRQLS group obtained an average score of $22.01(\mathrm{sd}=$ 7.40). The difference between these means was found to be highly significant $(p<0.000)$. In the delayed (30 minutes) recall administration of this instrument (ROM), the CRQHS group obtained a mean value of $10.71(\mathrm{sd}=5.40)$, and the CRQLS group obtained a mean value of $6.29(\mathrm{sd}=3.35)$. Once more, the difference between these two means was found to be highly significant $(p<0.000)$.

In the Revised Benton Visual Retention Test (BVR), the CRQHS group obtained an average score of $3.75(\mathrm{sd}=1.79)$. The corresponding value for the CRQLS group was 2.12 ( $\mathrm{sd}+$ 1.56). The difference between these two means was also found to be highly significant $(p<0.000)$.

\section{Discussion}

It is evident, on the bases of the results described above, that the level of cognitive reserve attained by the participants in this study has a significant and measurable impact on their neurocognitive status, as measured by an eclectic battery of neuropsychological instruments. This impact was seen clearly on the attentional and incidental memory abilities measured by the written and oral administrations of the Symbol Digit Test. The results obtained in this study also revealed the impact of cognitive reserve on the verbal fluency and word finding abilities measured by the Controlled Oral Word Association Test.

The level of cognitive reserve was also noted to have an impact on the naming function of language, as measured by the Boston Naming Test. In addition to this, the level of cognitive reserve was also found to have an impact on the visual constructional praxis abilities measured by the copy administration of the Rey Osterrieth Complex Figure Test, as well as the incidental memory functions assessed by the delayed memory administration of this instrument.

On the other hand, the impact of the level of cognitive reserve, as measured by the CRQ did have a clear impact on tasks in which memory was an important function. The results of the recall of the initial presentation of the supra-span list of words
(RAI) of the Rey Auditory Verbal Learning Test did not differ significantly between the two groups of patients.

Even though the mean values obtained by both groups in the fifth administration of the word list (RAV) and the delayed administration (RAD) showed statistical significance, the actual values differed by less than two (2) points. It is very difficult to make clinical decisions on the bases of such a narrow margin of difference. The same may be said of the visual memory functions assessed by the Revised Benton Visual Retention Test (BVR).

The interpretation of these findings brings out the ever present concern of the difference between statistical significance and clinical significance. Whereas these results show statistical significance, once again, it is very difficult to translate them into the clinical setting.

It should be noted that both groups did not perform well in measures related to memory processes. One possible explanation is the fact that these patients can be characterized as presenting what has been described as mild cognitive impairment of the amnestic type (now referred to as minor neurocognitive disorder), as they were referred to the Cognitive Health Program of MCCI, by their primary care physicians, for having reported to them memory difficulties to begin with.

\section{Conclusion and Recommendations}

The findings of this study clearly support the initial premise that there are things that can be done throughout the life cycle, to improve overall cognitive functioning in the later years of life. It is important to note that the sample included in this study is a referred sample, that is, patients referred for neuropsychological evaluation due to memory complaints. In this regard, it would be important to explore the impact of cognitive reserve on neuropsychological status of healthy, non-referred individuals, as well. It would also be important to replicate this study with patients that have begun to show symptoms of probable Alzheimer's disease.

The knowledge gained through this research can help in the development of life long strategies to improve or increase cognitive reserve. It can also point the way to the need for developing and implementing neurobehavioral interventions to lessen the impact of the aging process or the presence of medical conditions that may accelerate cognitive decline and result in functional impairments.

\section{REFERENCES}

Alberca Serrano, R. (1998). Demencias: Diagnóstico y tratamiento. Barcelona: Masson.

Albert, M. S., Dekowsky, S. T., Dickson, D., Dubois, B., Feldman, H. H., Fox, N. C., et al. (2013). The diagnosis of mild cognitive impairment due to Alzheimer's disease: Recommendations from the National Institute on Aging-Alzheimer's Association's Workgroups on Diagnostic Guidelines for Alzheimer's Disease. FOCUS, 11, 96-106. http://dx.doi.org/10.1176/appi.focus.11.1.96

American Psychiatric Association (2013). Diagnostic and statistical manual of mental disorders (5th ed.). Washington DC: American Psychiatric Association.

Benton, A. L. (2002). Test de retención visual de Benton: Manual (5th ed.). Madrid: TEA Ediciones, S.A.

Benton, A. L. (1974). Revised visual retention test (4th ed.), New York: The Psychological Corporation.

Kaplan, E. F., Goodglass, H., \& Weintraub, S. (1996). Test de vocabulario de Boston (2nd ed.). Buenos Aires: Editorial Médica Pa- 


\section{J. A. HERRERA PINO ET AL.}

namericana.

Kaplan, E. F., Goodglass, H., \& Weintraub, S. (1983). The Boston naming test (2nd ed.). Philadelphia (PA): Lea \& Febiger.

Lezak, M. D. Howieson, D. D., \& Loring, D. W. (2004). Neuropsychological assessment (4th ed.). New York: Oxford University Press.

Meyers, J. E., \& Meyers, K. R. (1995). Rey complex figure test and recognition trial. Odessa (FL): Psychological Assessment Resources.

Petersen, R. C. (2004). Mild cognitive impairment as a diagnostic entity. Journal of Internal Medicine, 256, 183-194. http://dx.doi.org/10.1111/j.1365-2796.2004.01388.x

Petersen, R. C., Doody, R., Kurz, A., Mohs, R. C., Morris, J. C., Rabins, P. V., Ritchie, K., Rossor, M., Leon Thal, L., \& Winblad, B. (2001). Current concepts in mild cognitive impairment. Archives of Neurology, 58, 1985-1992.

http://dx.doi.org/10.1001/archneur.58.12.1985

Petersen, R. C., Smith, G. E., Waring, S. C., Ivnik, R. J., Tangalos, E. G., \& Kokmen, E. (1999). Mild cognitive impairment: Clinical characterization and outcome. Archives of Neurology, 56, 303-308. http://dx.doi.org/10.1001/archneur.56.3.303

Rey, A. (2003). Test de copia y reproducción de memoria de figuras complejas (8th ed.). Madrid: TEA Ediciones, S.A.

Saxton, J., Ratcliff, G, Munro, C. A., Coffey, C. E., Becker, J. T., Fried, L., \& Kuller, L. (2000). Normative data on the Boston Naming Test and two equivalent 30-item short forms. The Clinical Neuropsychologist, 14, 526-534. http://dx.doi.org/10.1076/clin.14.4.526.7204
Schmidt, M. (1996). Rey Auditory verbal learning test: A handbook. Los Angeles (CA): Western Psychological Services.

Sivan, A. B. (1992). Benton visual retention test (5th ed.). San Antonio (TX): The Psychological Corporation.

Smith, A. (2002). SDMT: Test de símbolos y dígitos. Madrid: TEA Ediciones, S.A.

Smith, A. (1982). Symbol digit modalities test. Los Angeles (CA): Western Psychological Services.

Smith, A. (1973). Symbol digit modalities test. Los Angeles (CA): Western Psychological Services.

Spreen, O., \& Strauss, E. (1998). A compendium of neuropsychological tests (2nd ed.). New York: Oxford University Press.

Stern, Y. (2009). Cognitive reserve. Neuropsychologia, 47, 2015-2028. http://dx.doi.org/10.1016/j.neuropsychologia.2009.03.004

Stern, Y. (2006). Cognitive reserve and Alzheimer's disease. Alzheimer's Disease and Associated Disorders, 20, 112-117. http://dx.doi.org/10.1097/01.wad.0000213815.20177.19

Stern, Y. (2002). What is cognitive reserve? Theory and research application of the reserve concept. Journal of the International Neuropsychological Society, 8, 448-460. http://dx.doi.org/10.1017/S1355617702813248

Vasile, C. (2013). Cognitive reserve and cortical plasticity. ProcediaSocial and Behavioral Sciences, 78, 601-604. http://dx.doi.org/10.1016/j.sbspro.2013.04.359 